\title{
Superficial wall stress: the long awaited comprehensive biomechanical parameter to objectify and quantify our intuition
}

\author{
Juan Luis Gutiérrez-Chico ${ }^{1}$ (D) \\ Received: 12 May 2018 / Accepted: 26 May 2018 / Published online: 6 June 2018 \\ ๑) Springer Science+Business Media B.V., part of Springer Nature 2018
}

Keywords Intracoronary biomechanics $\cdot$ Superficial wall stress · Coronary artery disease

Even the most enthusiastic advocators of intracoronary biomechanics will come to admit that this scientific discipline has failed hitherto to translate into practical correlates for the interventional cardiologist. Of course, this is a fascinating research field, enlightening relevant processes like atherogenesis, plaque vulnerability, restenosis or neointimal healing after stenting, but no single practical hint could ever be derived from the biomechanical theory for the interventionalist. Only oscillatory shear stress seemed to offer a rationale to avoid step-up/step-down scenarios when a stent was implanted [1], but neither the evidence was so overwhelming, nor this concept gained widespread acceptance among the interventional community. Still the role of biomechanical factors in atherogenesis and other vascular processes is consistent: shear stress (SS) is a potent stimulus for the endothelium that determines the plaque distribution within the vessel [2-7] and the thickness of neointima after stenting in bare metal stents [8], drug-eluting stents [9-11] and bioresorbable scaffolds [12, 13]. Strain has been associated to plaque vulnerability [14-19], instead, and is calculated by elastography and palpography, based on radiofrequency tracking in grey-scale intravascular ultrasound (IVUS) cross-sections. Strain measures the radial stress in the cross-section due to the changes in blood pressure, which is about four orders of magnitude higher than the absolute value of SS and depends on the tissue composition of the vessel wall: a lipidic plaque is more strained than a fibrous one, when submitted to the same blood pressure. Therefore, the spots of high strain might represent potentially vulnerable plaques. Nonetheless, even though some indirect clinical evidence could support the concept [18], strain has failed

Juan Luis Gutiérrez-Chico

juanluis.gutierrezchico@ictra.es

1 Punta de Europa University Hospital, Crtra. Getares s/n, Algeciras (Cádiz) 11207, Spain to find a niche in the routine of the cathlab, because most of the vulnerable plaques, detected by whichever imaging method, remain indeed stable over time and only a few are substrate for future clinical events. In summary, most interventional operators have turned their back to the biomechanical fundamentals, ignoring them in their routine practice, and just appealing to them from time to time as if they were an arcane force that can explain (or be blamed for) any kind of weird or inconvenient finding.

This panorama could however change soon. Leaving SS aside and focusing on biomechanics of high magnitude, like strain, they have been based on cross-sectional analysis so far, which is an important limitation, because the coronary vessels are submitted to other vectors of mechanical stress (Fig. 1), which are elusive to a cross-sectional analysis. Besides the blood pressure, during the cardiac cycle the systo-diastolic motion stresses the coronary vessels in different ways: longitudinal compression/stretching, bending and twisting. The concept of plaque structural stress (PSS) is meant to integrate the strain of all these mechanical vectors, but in practice it is calculated by finite element analysis (FEA), entering the vessel geometry, the plaque composition of the vessel wall and different haemodynamic parameters into the equation [20-22]. Therefore, when calculated this way, PSS essentially neglects the vectors depending on the systo-diastolic motion and ends up estimating the strain dependent on the blood pressure, but following a different method of calculation (Fig. 1). In the current issue of Int $\mathrm{J}$ Cardiovasc Imaging, Wu et al. validate a novel biomechanical parameter, namely superficial wall stress (SWS), that integrates for the first time all the mechanical vectors of high magnitude stressing the vessel: blood pressure, stretching, bending and twisting [23]. It is hence quite close to the theoretical concept of PSS, but concentrating on the intimal surface of the vessel. The key difference is that the authors analyse the deformation of the luminogram in all the 


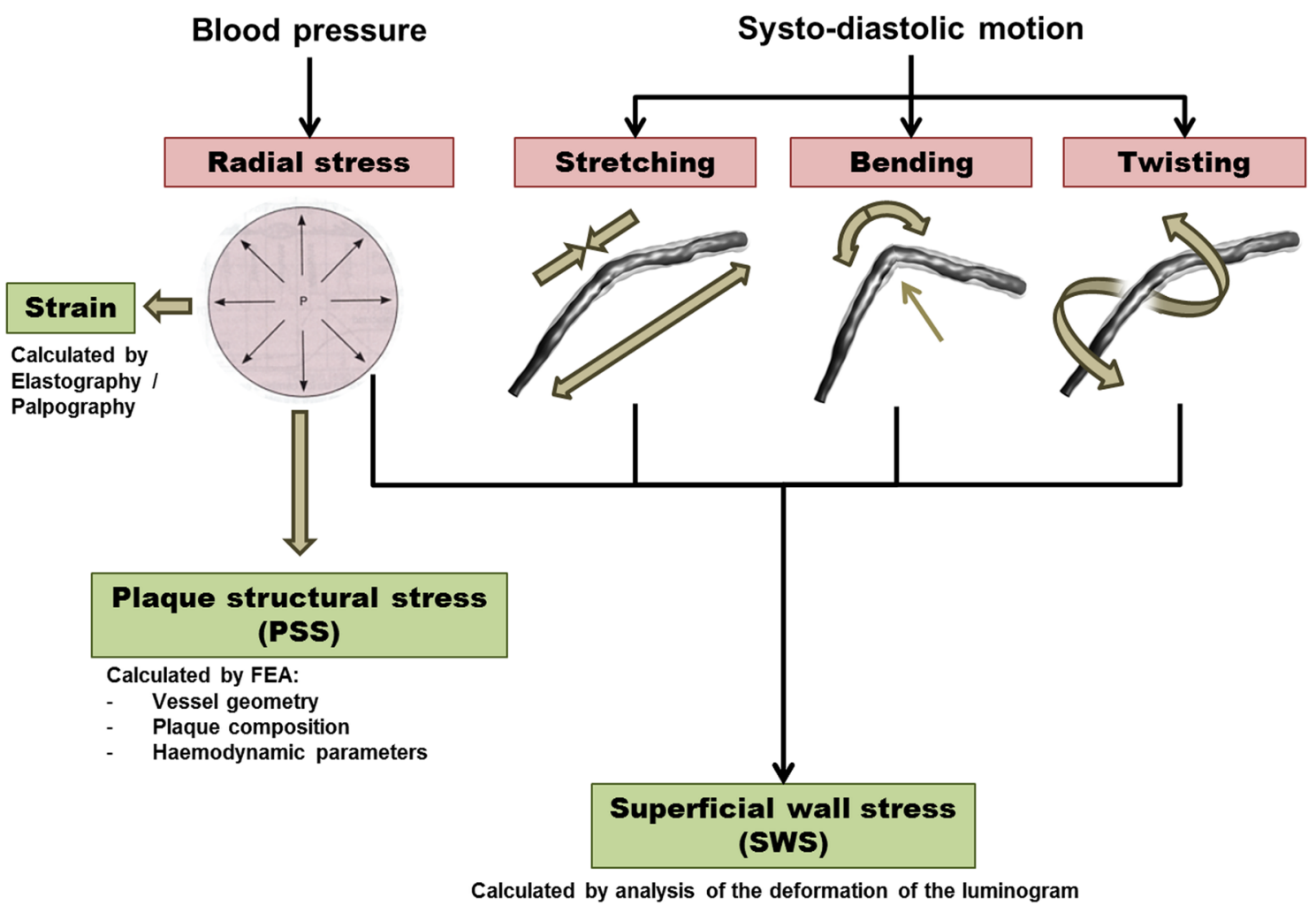

Fig. 1 Different mechanical vectors straining the coronary vessel and their relation to strain, plaque structural stress and superficial wall stress. FEA finite element analysis

abovementioned vectors, instead of solving complex equations in FEA [24, 25]. They need to know neither the plaque composition along the vessel nor any other haemodynamic parameters: all is implied in the final deformation over the cardiac cycle.

The potential for this novel parameter is sizeable. Firstly, because of its appealing simplicity: all the required information for such a comprehensive biomechanical assessment can be obtained by a simple coronary angiography. This enables the widespread application of SWS in all kind of clinical settings. The authors focus initially on the potential to detect vulnerable coronary spots, because SWS offers much more information than just strain, but SWS can have many more potential applications. Interventional cardiologists have intuitively avoided to stent regions submitted to high mechanical stress, like muscular bridging, or segments submitted to extreme bending or compression in systole. They tend to believe that coronary devices perform poorly under these circumstances, but their identification still relies on a subjective and intuitive evaluation of the coronary angiography. SWS can finally provide an objective and quantitative assessment of the stress due to stretching/compression, bending and twisting of each coronary segment, thus opening an interesting door to study the fatigue of coronary devices and to reduce the risk of stent or scaffold failure.
Last but not least, SWS is calculated with a similar approach to the one required to obtain quantitative flow ratio (QFR) $[26,27]$ and could be probably simplified in a near future. It could come soon the time when a coronary angiography could provide us with information about the physiologic relevance of a stenosis (QFR), while pointing out potential spots of plaque instability (SWS). For quite some time the perspective of coronary biomechanics was not so promising as it is now. The authors must be congratulated for having revolutionised coronary angiography, by squeezing the functional and biomechanical information that can be objectively derived from it. Whether SWS will finally succeed in translating into practical consequences for the interventional cardiologist is still a mystery, but the door is open and the path is clear.

\section{Compliance with ethical standards}

Conflict of interest The author has no conflict of interests to disclose.

\section{References}

1. Thury A, Wentzel JJ, Vinke RVH, Gijsen FJH, Schuurbiers JCH, Krams R, de Feyter PJ, Serruys PW, Slager CJ (2002) Focal 
in-stent restenosis near step-up: roles of low and oscillating shear stress? Circulation 105(23):e185-e187

2. Malek AM, Alper SL, Izumo S (1999) Hemodynamic shear stress and its role in atherosclerosis. JAMA 282(21):2035-2042

3. Cheng C, Tempel D, van Haperen R, van der Baan A, Grosveld F, Daemen MJ, Krams R, de Crom R (2006) Atherosclerotic lesion size and vulnerability are determined by patterns of fluid shear stress. Circulation 113(23):2744-2753

4. Kirpalani A, Park H, Butany J, Johnston KW, Ojha M (1999) Velocity and wall shear stress patterns in the human right coronary artery. J Biomech Eng 121(4):370-375

5. Wentzel JJ, Janssen E, Vos J, Schuurbiers JC, Krams R, Serruys PW, de Feyter PJ, Slager CJ (2003) Extension of increased atherosclerotic wall thickness into high shear stress regions is associated with loss of compensatory remodeling. Circulation 108(1):17-23

6. Asakura T, Karino T (1990) Flow patterns and spatial distribution of atherosclerotic lesions in human coronary arteries. Circ Res 66(4):1045-1066

7. Tadjfar M (2004) Branch angle and flow into a symmetric bifurcation. J Biomech Eng 126(4):516-518

8. Wentzel JJ, Krams R, Schuurbiers JC, Oomen JA, Kloet J, van der Giessen WJ, Serruys PW, Slager CJ (2001) Relationship between neointimal thickness and shear stress after Wallstent implantation in human coronary arteries. Circulation 103(13):1740-1745

9. Tanabe K, Gijsen FJH, Degertekin M, Ligthart JMR, Oortman RM, Serruys PW, Slager CJ (2002) True three-dimensional reconstructed images showing lumen enlargement after sirolimus-eluting stent implantation. Circulation 106(22):e179-e180

10. Gijsen FJH, Oortman RM, Wentzel JJ, Schuurbiers JCH, Tanabe K, Degertekin M, Ligthart JM, Thury A, de Feyter PJ, Serruys PW, Slager CJ (2003) Usefulness of shear stress pattern in predicting neointima distribution in sirolimus-eluting stents in coronary arteries. Am J Cardiol 92(11):1325-1328

11. Foin N, Gutierrez-Chico JL, Nakatani S, Torii R, Bourantas CV, Sen S, Nijjer S, Petraco R, Kousera C, Ghione M, Onuma Y, Garcia-Garcia HM, Francis DP, Wong P, Di MC, Davies JE, Serruys PW (2014) Incomplete stent apposition causes high shear flow disturbances and delay in neointimal coverage as a function of strut to wall detachment distance: implications for the management of incomplete stent apposition. Circ Cardiovasc Interv 7:180-189

12. Gutiérrez-Chico JL, Gijsen FJH, Regar E, Wentzel JJ, De Bruyne B, Thuesen L, Ormiston JA, McClean D, Windecker S, Chévalier B, Dudek D, Whitbourn R, Brugaletta S, Serruys PW (2012) Differences in neointimal thickness between the adluminal and the abluminal sides of malapposed and side-branch struts: evidence in vivo about the abluminal healing process. JACC Cardiovasc Interv 16(4):428-435

13. Karanasos A, Li Y, Tu S, Wentzel JJ, Reiber JH, van Geuns RJ, Regar E (2015) Is it safe to implant bioresorbable scaffolds in ostial side-branch lesions? Impact of 'neo-carina' formation on main-branch flow pattern. Longitudinal clinical observations. Atherosclerosis 238(1):22-25

14. de Korte CL, Pasterkamp G, van der Steen AFW, Woutman HA, Bom N (2000) Characterization of plaque components with intravascular ultrasound elastography in human femoral and coronary arteries in vitro. Circulation 102(6):617-623

15. de Korte CL, Sierevogel MJ, Mastik F, Strijder C, Schaar JA, Velema E, Pasterkamp G, Serruys PW, van der Steen AFW (2002) Identification of atherosclerotic plaque components with intravascular ultrasound elastography in vivo: a yucatan pig study. Circulation 9(14): 1627-1630

16. de Korte CL, Carlier SG, Mastik F, Doyley MM, van der Steen AFW, Serruys PW, Bom N (2002) Morphological and mechanical information of coronary arteries obtained with intravascular elastography. Feasibility study in vivo. Eur Heart J 23(5):405-413

17. Schaar JA, de Korte CL, Mastik F, Strijder C, Pasterkamp G, Boersma E, Serruys PW, van der Steen AFW. (2003) Characterizing vulnerable plaque features with intravascular elastography. Circulation 108(21):2636-2641

18. Schaar JA, Regar E, Mastik F, McFadden EP, Saia F, Disco C, de Korte CL, de Feyter PJ, van der Steen AF, Serruys PW (2004) Incidence of high-strain patterns in human coronary arteries: assessment with three-dimensional intravascular palpography and correlation with clinical presentation. Circulation 109(22):2716-2719

19. Schaar JA, van der Steen AF, Mastik F, Baldewsing RA, Serruys PW (2006) Intravascular palpography for vulnerable plaque assessment. J Am Coll Cardiol 47(8 Suppl):C86-C91

20. Ohayon J, Dubreuil O, Tracqui P, Le FS, Rioufol G, Chalabreysse L, Thivolet F, Pettigrew RI, Finet G (2007) Influence of residual stress/strain on the biomechanical stability of vulnerable coronary plaques: potential impact for evaluating the risk of plaque rupture. Am J Physiol Heart Circ Physiol 293(3):H1987-H1996

21. Teng Z, Brown AJ, Calvert PA, Parker RA, Obaid DR, Huang Y, Hoole SP, West NE, Gillard JH, Bennett MR (2014) Coronary plaque structural stress is associated with plaque composition and subtype and higher in acute coronary syndrome: the BEACON I (Biomechanical Evaluation of Atheromatous Coronary Arteries) study. Circ Cardiovasc Imaging 7(3):461-470

22. Costopoulos C, Huang Y, Brown AJ, Calvert PA, Hoole SP, West NEJ, Gillard JH, Teng Z, Bennett MR (2017) Plaque rupture in coronary atherosclerosis is associated with increased plaque structural stress. JACC Cardiovasc Imaging 10(12):1472-1483

23. Wu X, von Birgelen C, Li Z, Zhang S, Huang J, Liang F, Li Y, Wijns W, Tu S (2018) Assessment of superficial coronary vessel wall deformation and stress: validation of in silico models and human coronary arteries in vivo. Int J Cardiovasc Imaging. https ://doi.org/10.1007/s10554-018-1311-7

24. Wu X, von Birgelen C, Muramatsu T, Li Y, Holm NR, Reiber JHC, Tu S (2017) A novel four-dimensional angiographic approach to assess dynamic superficial wall stress of coronary arteries in vivo: initial experience in evaluating vessel sites with subsequent plaque rupture. EuroIntervention 13(9):e1099-e1103

25. Wu X, von Birgelen C, Tu W Wijns W, Tu S (2017) Superficial wall stress assessed from 4-D analysis of coronary angiography in vivo. Int J Cardiovasc Imaging 33(7):1111-1112

26. Tu S, Barbato E, Koszegi Z, Yang J, Sun Z, Holm NR, Tar B, Li Y, Rusinaru D, Wijns W, Reiber JH (2014 July) Fractional flow reserve calculation from 3-dimensional quantitative coronary angiography and TIMI frame count: a fast computer model to quantify the functional significance of moderately obstructed coronary arteries. JACC Cardiovasc Interv 7(7):76847-76877

27. Tu S, Westra J, Yang J, von BC, Ferrara, Pellicano A, Nef M, Tebaldi H, Murasato M, Lansky Y, Barbato A, van der Heijden E, Reiber LC, Holm JH, Wijns NR (2016) W. Diagnostic accuracy of fast computational approaches to derive fractional flow reserve from diagnostic coronary angiography: the International Multicenter FAVOR pilot study. JACC Cardiovasc Interv 9(19):2024-2035 